\title{
2016 National Rheumatic Fever Week: The status of rheumatic heart disease in South Africa
}

Over 25 years ago, the National Department of Health (NDoH) declared the first week of August National Rheumatic Fever Week following the efforts of John Barlow, Budgie van der Merwe and others to focus the attention of the nation on the need to implement proven interventions to reduce the incidence of acute rheumatic fever (ARF) and the prevalence of rheumatic heart disease (RHD).$^{[1,2]}$ It was at this time that ARF was made a notifiable condition, although the uptake of notification was subsequently found to be suboptimal. ${ }^{[3]}$ In October 2005, the NDoH hosted the 1st Pan-African Workshop on Acute Rheumatic Fever and Rheumatic Heart Disease, together with the World Health Organization (Africa Region), the World Heart Federation, the Pan-African Society of Cardiology and the South African Heart and Stroke Foundation, where the Drakensberg Declaration was adopted. ${ }^{[4]}$ The Drakensberg conference issued a clarion call to African governments and their ministries of health to initiate national programmes to eliminate ARF and control RHD by raising awareness among the public and professionals, measurement of the burden of disease through surveillance studies, improvement of medical and surgical care through advocacy, and the widespread use of penicillin in primary and secondary prevention activities (the A.S.A.P. Programme) ${ }^{[5]}$

A.S.A.P. has inspired new research that has provided vital information on the status of ARF and RHD in Africa and the world. ${ }^{[6]}$ South African (SA) studies reveal a changing pattern of disease at hospital and population levels. Hospital-based studies show a high incidence of congestive heart failure caused by RHD (average of 25 cases/100 000/year in Soweto) that is associated with high 60-day and 180 -day mortality rates of $24.8 \%$ (95\% confidence interval (CI) 13.6 - 42.5) and $35.4 \%$ (95\% CI 21.6 - 54.4), respectively. ${ }^{[7,8]}$ This high burden of heart failure and mortality in adults has to be contrasted with a falling caseload of ARF and RHD in children, as demonstrated in Soweto recently (Fig. 1). Furthermore, there has been a fall in causespecific mortality from RHD over the past 15 years (Fig. 2). These changes are consistent with a transition of ARF/RHD from a condition of childhood to a mature endemic disease of adults. The changes may reflect a 'Mandela dividend' associated with the improvement in access to primary healthcare and rising socioeconomic status of South Africans since the advent of the new SA in 1994. ${ }^{\left[{ }^{[9]}\right.}$

The 'In Practice' article in this issue of SAMJ on the role of screening echocardiography for RHD in the school health programme by Shung-King et al. ${ }^{[10]}$ and the letter describing a regimen for the painless administration of intramuscular penicillin by Madeira et al..$^{[1]}$ address important issues in the quest to end RHD. The commentary by Shung-King et al. ${ }^{[10]}$ is a response to an echocardiographic screening study of schoolchildren in Cape Town that showed a prevalence of latent RHD of 20 - 30 per 1000 among asymptomatic schoolchildren, although about $50 \%$ of these cases revert to normal after 5 years of follow-up. ${ }^{[12,13]}$ Screening echocardiography is not recommended as a routine test in the school health programme until studies of its impact on prognosis and costeffectiveness are conducted. ${ }^{10,14]}$ The advice by Madeira et al. ${ }^{[1]}$ on the use of lignocaine as a diluent for benzathine penicillin is relevant not only to practitioners who use injectable penicillin on a regular basis for the primary and secondary prevention of ARF, but also to those whose patients need penicillin prophylaxis against recurrent infections in sickle cell disease and immune deficiencies. ${ }^{[15,16]}$

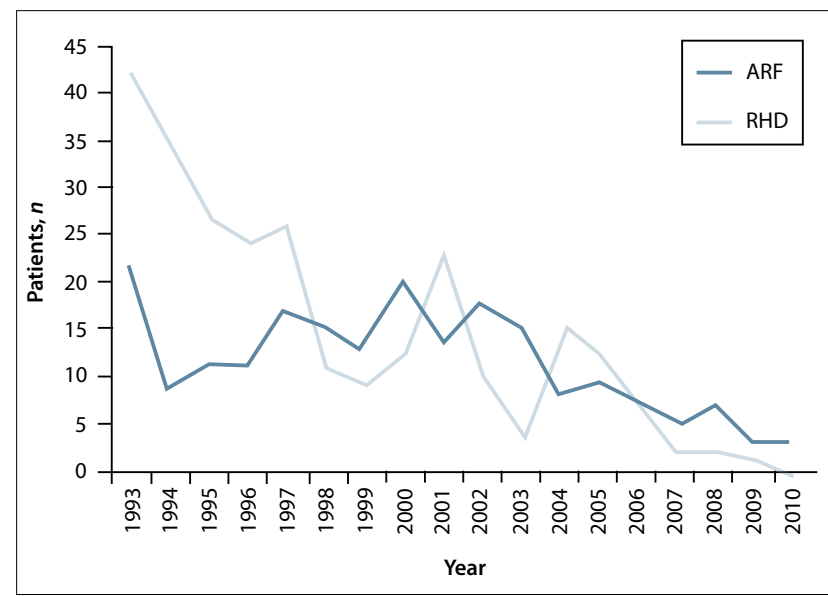

Fig. 1. Number of cases of ARF and RHD presenting to the Paediatric Cardiology Unit at Chris Hani Baragwanath Hospital, Johannesburg, 1993 2010.

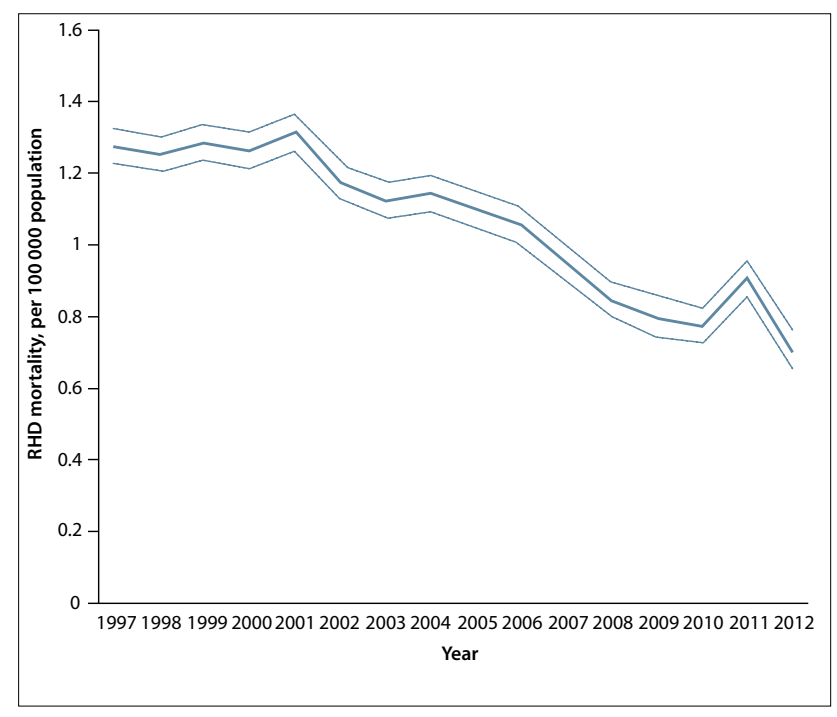

Fig. 2. Cause-specific mortality rate due to RHD in the SA population, 1997 2012. (Dotted lines $=$ the confidence intervals of the estimates of mortality.)

There has been significant progress in the uptake of the A.S.A.P. call by African governments. In June 2015, the heads of state of African countries endorsed the Addis Ababa Communiqué, which sets out seven actions for addressing the barriers to RHD control that were identified in the REMEDY study. ${ }^{[17,18]}$ These are as follows: (i) creation of prospective disease registers at sentinel sites in affected countries to measure disease burden and track progress towards the reduction of mortality by $25 \%$ by the year 2025 , as mandated by the World Health Organization; ${ }^{[19]}$ (ii) provision of an adequate supply of high-quality benzathine penicillin for primary and secondary prevention; (iii) improvement of access to reproductive health services for women with RHD and other non-communicable diseases (NCDs); (iv) decentralisation of technical expertise and technology for diagnosing and managing ARF and RHD (including ultrasound of the heart); $(v)$ establishment of national and regional centres of 
excellence for essential cardiac surgery for the treatment of affected patients and the training of cardiovascular practitioners of the future; (vi) initiation of national multisectoral RHD programmes within NCD control programmes of affected countries; and (vii) fostering of international partnerships with multinational organisations for resource mobilisation, monitoring and evaluation of the programme to end RHD in Africa. ${ }^{[18]}$

SA has the conditions that are required for success in eradicating $\mathrm{ARF}$ and ending RHD. The $\mathrm{NDoH}$ has prioritised the prevention of the disease through initiatives such as National Rheumatic Fever Week, the inclusion of ARF among notifiable conditions, and efforts to improve access to primary healthcare. Health practitioners need to play their role by notifying cases of ARF, treating all children with a sore throat with penicillin according to the SA guidelines, ${ }^{[20]}$ and entering all our patients with RHD in the electronic register. ${ }^{[21]}$ These measures, together with other actions outlined in the Addis Ababa Communiqué, if implemented across the health system, will hasten the demise of ARF and bring RHD under control by the year 2025.

\section{Bongani M Mayosi}

Department of Medicine, Groote Schuur Hospital and Faculty of Health Sciences, University of Cape Town, South Africa bongani.mayosi@uct.ac.za

1. McLaren MJ, Hawkins DM, Koornhof HJ, et al. Epidemiology of rheumatic heart disease in black school children of Soweto, Johannesburg. BMJ 1975;3(5981):474-478. DOI:10.1136/bmj.3.5981.474
. Lawrenson J. Tribute to Professor Pieter-Luttig van der Merwe. 2015. https://www.saheart.org/ newsletters/viewFile/53 (accessed 2 July 2016).

3. Nkgudi B, Robertson KA, Volmink J, Mayosi BM. Notification of rheumatic fever in South Africa - evidence for underreporting by health care professionals and administrators. S Afr Med 2006;96(3):206-208

4. Mayosi B, Robertson K, Volmink J, et al. The Drakensberg declaration on the control of rheumatic fever and rheumatic heart disease in Africa. S Afr Med J 2006:96(3):246.
5. Robertson KA, Volmink JA, Mayosi BM. Towards a uniform plan for the control of rheumatic fever and rheumatic heart disease in Africa - the Awareness Surveillance Advocacy Prevention (A.S.A.P.) Programme. S Afr Med J 2006;96(3):241-245.

6. Mayosi BM, Gamra H, Dangou J-M, Kasonde J. Rheumatic heart disease in Africa: The Mosi-o-Tunya call to action. Lancet Glob Health 2014;2(8):e438-e439. DOI:10.1016/S2214$109 \mathrm{X}(14) 70234-7$

7. Sliwa K, Carrington M, Mayosi BM, Zigiriadis E, Mvungi R, Stewart S. Incidence and characteristics of newly diagnosed rheumatic heart disease in urban African adults: Insights from the Heart of Soweto Study. Eur Heart J 2010;31(6):719-727. DOI:10.1093/eurheartj/ehp530

8. Zühlke LJ, Engel ME, Watkins D, Mayosi BM. Incidence, prevalence and outcome of rheumatic heart disease in South Africa: A systematic review of contemporary studies. Int J Cardiol 2015;199:375-383. DOI:10.1016/j.ijcard.2015.06.145

. Mayosi BM, Benatar SR. Health and health care in South Africa - 20 years after Mandela. N Engl J Med 2014:371(14):1344-1353. DOI:10.1056/NEJMsr1405012

10. Shung-King M, Engel ME, Zuhlke L, Mayosi BM. Asymptomatic rheumatic heart disease in South African schoolchildren: Implications for addressing chronic health conditions through a school health service. S Afr Med J 2016;106(8):761-762. DOI:10.7196/SAMJ.2016. v106i8.10756

11. Madeira G, Mocumbi AO, Mayosi BM. Advice to health professionals: Use of lignocaine as a diluent to reduce the pain associated with the administration of benzathine penicillin G. S Afr Med J 2016:106(8):742. DOI:10.7196/SAMJ2016.v106i8.10864

12. Engel ME, Haileamlak A, Zühlke L, et al. Prevalence of rheumatic heart disease in 4720 asymptomatic scholars from South Africa and Ethiopia. Heart 2015;101(17):1389-1394. DOI:10.1136/ heartinl-2015-30744

13. Zuhlke L, Engel M, Lemmer C, et al. The natural history of latent rheumatic heart disease in a 5 year follow-up study: A prospective observational study. BMC Cardiovasc Disord 2016;16(1):46. DOI:10.1186/s12872-016-0225-3

14. Zühlke L, Mayosi BM. Echocardiographic screening for subclinical rheumatic heart disease remains a research tool pending studies of impact on prognosis. Curr Cardiol Rep 2013;15(3):343. DOI:10.1007/ s11886-012-0343-1

15. Duncan NA, Kronenberger WG, Hampton KC, et al. A validated measure of adherence to antibiotic prophylaxis in children with sickle cell disease. Patient Prefer Adherence 2016;10:983-992. DOI:10.2147/PPA.S103874

16. Owen EP, Leisegang F, Whitelaw A, et al. Complement component C5 and C6 mutation screening indicated in meningococcal disease in South Africa. S Afr Med J 2012;102(6):525-527.

17. Zühlke L, Engel ME, Karthikeyan G, et al. Characteristics, complications, and gaps in evidence-based interventions in rheumatic heart disease: The Global Rheumatic Heart Disease Registry (the REMEDY study). Eur Heart J 2015;36(18):1115-1122. DOI:10.1093/eurheartj/ehu449

18. Watkins D, Zuhlke L, Engel M, et al. Seven key actions to eradicate rheumatic heart disease in Africa: The Addis Ababa Communiqué. Cardiovasc J Afr 2016;27(3):184-187. DOI:10.5830/CVJA-2015-090 19. World Health Organization. Global Action Plan for the Control and Prevention of Noncommunicable Disease 2013-2020. Geneva: WHO, 2013

20. South African National Department of Health. National Guidelines on the Primary Prevention and Prophylaxis of Rheumatic Fever and Rheumatic Heart Disease for Health Professionals at Primary Level. Pretoria: $\mathrm{NDoH}, 1997$

21. Van Dam J, Musuku J, Zuhlke LJ, et al. An open-access, mobile compatible, electronic patient register for rheumatic heart disease ('eRegister') based on the World Heart Federation's framework for patient registers. Cardiovasc J Afr 2015;26(6):227-233. DOI:10.5830/CVJA-2015-058

S Afr Med J 2016;106(8):740-741. DOI:10.7196/SAMJ.2016.v106i8.10561 